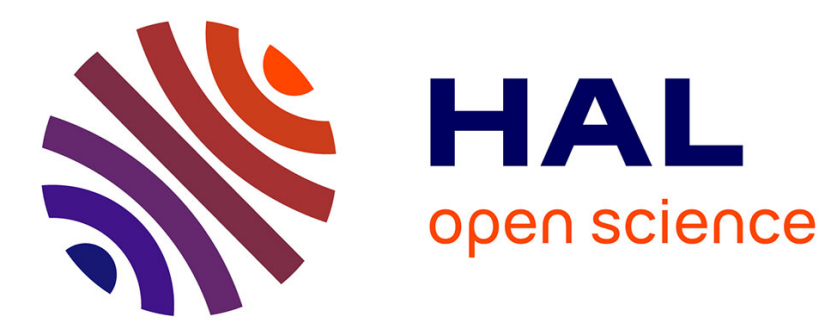

\title{
Sampling and isolation of C. elegans from the Natural habitat.
}

\author{
Nausicaa Poullet, Christian Braendle
}

\section{To cite this version:}

Nausicaa Poullet, Christian Braendle. Sampling and isolation of C. elegans from the Natural habitat.. C. Elegans: Methods and Applications, 1327, 2015, Methods in Molecular Biology, 10.1007/978-14939-2842-2_16. hal-02799232

\section{HAL Id: hal-02799232 \\ https://hal.inrae.fr/hal-02799232}

Submitted on 5 Jun 2020

HAL is a multi-disciplinary open access archive for the deposit and dissemination of scientific research documents, whether they are published or not. The documents may come from teaching and research institutions in France or abroad, or from public or private research centers.
L'archive ouverte pluridisciplinaire HAL, est destinée au dépôt et à la diffusion de documents scientifiques de niveau recherche, publiés ou non, émanant des établissements d'enseignement et de recherche français ou étrangers, des laboratoires publics ou privés. 


\title{
Sampling and Isolation of $C$. elegans from the Natural Habitat
}

\section{Nausicaa Poullet and Christian Braendle}

\begin{abstract}
Wild populations of the model organism C. elegans allow characterization of natural genetic variation underlying diverse phenotypic traits. Here we provide a simple protocol on how to sample and rapidly identify C. elegans wild isolates. We outline how to find suitable habitats and organic substrates, followed by describing isolation and identification of C. elegans live cultures based on easily recognizable morphological characteristics, molecular barcodes and/or mating tests. This protocol uses standard laboratory equipment and requires no prior knowledge of C. elegans biology.
\end{abstract}

Key words Caenorhabditis elegans, Natural genetic variation, Natural populations, Wild isolates, Natural habitat, Ecology

\section{Introduction}

Insights into $C$. elegans biology are almost exclusively based on the analysis of a single reference strain (N2) but recent research has started to investigate genetic and phenotypic variation among C. elegans wild isolates [1]. Key findings are that the reference strain $\mathrm{N} 2$ shows extensive laboratory adaptation $[2,3]$ and that $C$. elegans natural populations show overall very little genetic differentiation across the globe [4]. Nevertheless, C. elegans wild isolates may exhibit marked phenotypic differences, some of which have been genetically and molecularly characterized using quantitative genetic mapping approaches [1]. Such characterization of C. elegans natural variation generates novel insights into C. elegans biology and further places the wealth of mechanistic knowledge of this model organism into a much-needed ecological and evolutionary context [5].

Hundreds of C. elegans isolates have been collected worldwide, and the species is clearly more abundant in temperate than in tropical regions [4-8] (Fig. 1). The few C. elegans isolates found in the tropics occurred mostly at high altitude $[8,9]$ and indicate, consistent with experimental determination of thermal optima in 


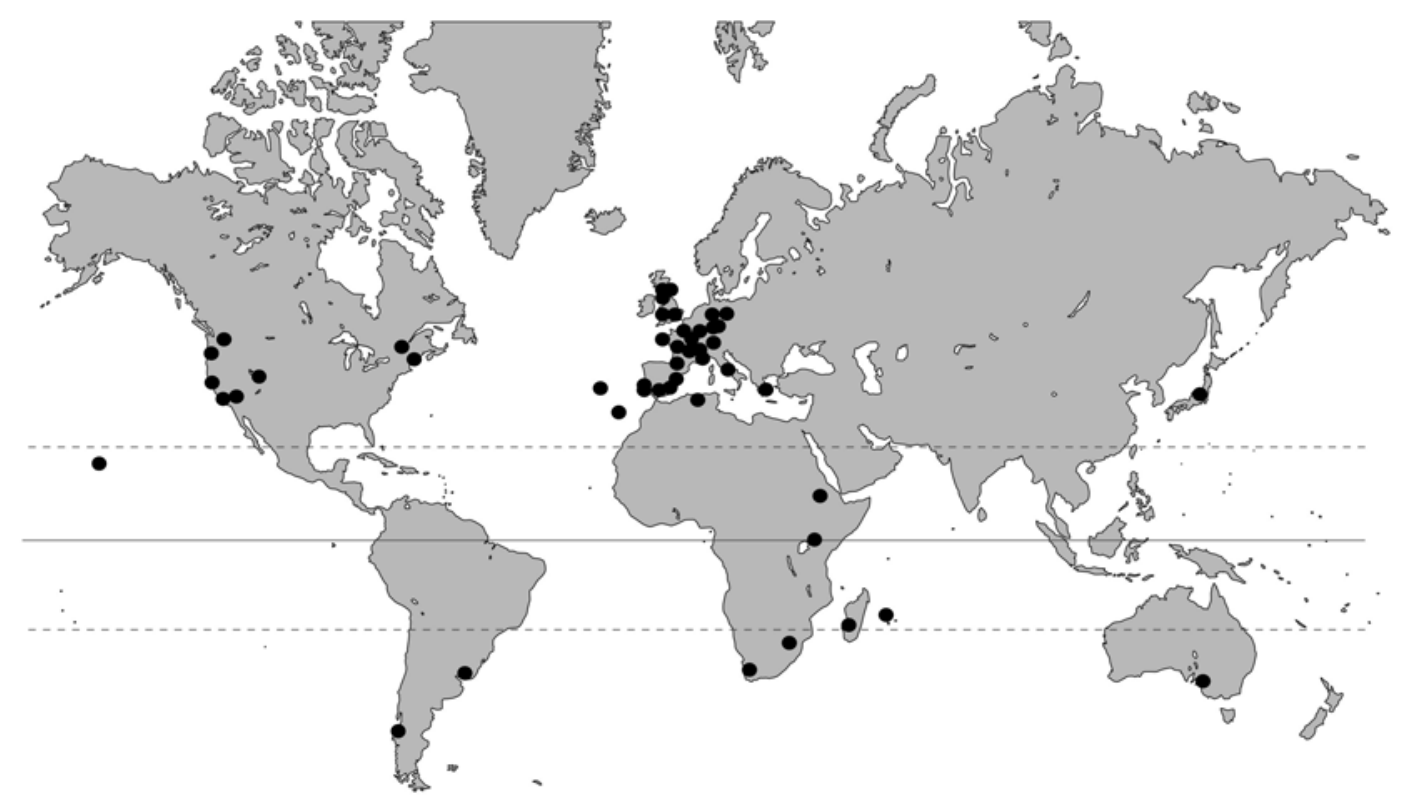

Fig. 1 Geographic distribution of $C$. elegans wild isolates (adapted from refs. $[4,7,13,15]$ and C. Braendle, unpublished data). A list of available $C$. elegans wild isolates can be consulted at http://www.wormbase.org/ species/c_elegans/strain\#2-10-5. For information on other Caenorhabditis species, see [8] and for updates on species discovery, see http://evolution.wormbase.org/index.php/Main_Page

the laboratory [10], that C. elegans does not tolerate prolonged exposure to temperatures above $25^{\circ} \mathrm{C}$.

Current insights into the global distribution of C. elegans are limited due to strong sampling bias, with some regions (e.g., France) having been frequently sampled [5, 6, 11-13] whereas others (e.g., Eastern Europe) have never or only rarely been sampled. Although it is likely to colonize highly diverse habitats, C. elegans has primarily been isolated from anthropogenic habitats, such as gardens or agricultural lands [11-17], and only very rarely from more unperturbed sites (e.g., forests) [13], which still await in-depth sampling for C. elegans.

C. elegans and other Caenorhabditis species have been isolated from a wide variety of organic substrates, mainly decomposing vegetal matter, such as compost, fruits or plant stems $[8,18]$. Despite commonly being referred to as a soil nematode, C. elegans has virtually never been isolated from soil samples but mostly from decaying vegetal matter on or above the soil layer. C. elegans has also been isolated from a range of live or dead invertebrates (e.g., beetles, isopods, millipedes, snails, and slugs) [4-6, 11, 13]. Note that in contrast to other nematode species there is no strong evidence for taxon-specific phoretic or necromenic invertebrate associations of C. elegans $[5,19]$. 
In this chapter we provide a simple protocol for sampling and isolation of $C$. elegans wild isolates, chiefly aimed at researchers having minimal working knowledge using $C$. elegans as a study organism. Nevertheless, acquiring basic knowledge of C. elegans handling and maintenance as presented in [20] is highly recommended. Note that several alternative, yet usually more timeconsuming nematode isolation protocols are available [6].

\section{Materials}

\subsection{Collection and Storage of Substrate Samples}

\subsection{Nematode} Isolation in the Laboratory

\subsection{Morphological and Molecular Identification of C. elegans}

\subsection{Genetic Identification Through Crosses with Established C. elegans Strains}

1. Sampling containers, e.g., resistant plastic zip-lock bags.

2. Disposable plastic gloves.

1. Dissecting stereomicroscope with transmitted light source (5-50× magnification).

2. Nematode growth medium (NGM) [20]: $1 \mathrm{~L}: 3 \mathrm{~g} \mathrm{NaCl}, 25 \mathrm{~g}$ agar, $2.5 \mathrm{~g}$ Bacto Peptone, $975 \mathrm{~mL} \mathrm{H}_{2} \mathrm{O}$. After autoclaving, add $1 \mathrm{~mL} 1 \mathrm{M} \mathrm{CaCl}_{2}, 1 \mathrm{~mL} 5 \mathrm{mg} / \mathrm{mL}$ cholesterol in ethanol, $1 \mathrm{~mL} 1 \mathrm{M} \mathrm{MgSO}_{4}$, and $25 \mathrm{~mL} 1 \mathrm{M} \mathrm{KPO}_{4}$. Mix well and dispense solution in Petri dishes (e.g., 90 and $55 \mathrm{~mm}$ diameter). (The increased agar concentration $(2.5 \%$ instead of the usual $1.7 \%$ helps preventing burrowing of nematodes into the culture plates). Store at room temperature for 2-4 days.

3 . Seed NGM plates with a central spot of E. coli OP50 (100$200 \mu \mathrm{L})$ and store at room temperature for 2-4 days. OP50 is available from the Caenorhabditis Genetics Center (CGC): http://www.cbs.umn.edu/research/resources/cgc.

4. Disposable plastic gloves.

5. Clean water or M9 buffer (1 L): $3 \mathrm{~g} \mathrm{KH}_{2} \mathrm{PO}_{4}, 6 \mathrm{~g} \mathrm{Na} \mathrm{HPO}_{4}$, $5 \mathrm{~g} \mathrm{NaCl}$; autoclave; add $1 \mathrm{~mL} 1 \mathrm{M} \mathrm{MgSO}_{4}$ before use [20].

6. Platinum worm pick [20].

7. Parafilm.

1. Dissecting stereomicroscope with transmitted light source $(50 \times-100 \times$ magnification $)$.

2. Standard PCR reagents and equipment and access to sequencing service.

1. Dissecting stereomicroscope with transmitted light source (5-50× magnification).

2. Identified C. elegans strain, e.g., N2 (available from the CGC: http://www.cbs.umn.edu/research/resources/cgc).

3. NGM plates ( $55 \mathrm{~mm}$ diameter) (see Subheading 2.2, item 2 ). 


\subsection{Establishment and Cryopreservation of C. elegans Wild Isolate Stocks}

1. NGM plates ( $55 \mathrm{~mm}$ diameter) (see Subheading 2.2, item 2).

2. Freezing solution [20]: $300 \mathrm{~mL}$ : Start with $100 \mathrm{~mL}$ of $\mathrm{dH}_{2} \mathrm{O}$ and add $1.76 \mathrm{~g} \mathrm{NaCl}, 2.04 \mathrm{~g} \mathrm{KH}_{2} \mathrm{PO}_{4}, 1.7 \mathrm{~mL}$ of $1 \mathrm{M} \mathrm{NaOH}$, $1.2 \mathrm{~g}$ agar, $71.6 \mathrm{~mL}$ glycerol. Heat to boiling until the agar is dissolved. Bring to $300 \mathrm{~mL}$ with $\mathrm{dH}_{2} \mathrm{O}$. Distribute $50 \mathrm{~mL}$ per $100 \mathrm{~mL}$ bottles; autoclave. After autoclaving or when first using, add $1.5 \mathrm{~mL} 0.1 \mathrm{M} \mathrm{MgSO}_{4}$ and $100 \mu \mathrm{L} 1 \mathrm{M} \mathrm{CaCl}_{2}$ per $50 \mathrm{~mL}$ bottle $[6,20]$.

3. Cryovials $(2 \mathrm{~mL})$.

4. $-80{ }^{\circ} \mathrm{C}$ freezer and liquid nitrogen storage facilities.

\section{Methods}

\subsection{Finding Suitable Habitats and Substrate Samples}

Potentially, C. elegans may be found in diverse, anthropogenic as well as unperturbed natural sites; however, the latter have rarely been sampled. In temperate regions of France, temporal sampling of natural populations uncovered C. elegans from September to November, but rarely during the summer months [13]. Such population fluctuations further depend on the specific habitat and substrate sampled, given that certain habitats, e.g., composts heaps in gardens [12], may represent more stable habitats than others, such as, seasonally occurring fruits. As a general rule, hot, dry or very cold habitats are very unlikely to yield C. elegans although individuals in the dauer stage may be uncovered at low densities.

Substrates potentially containing $C$. elegans encompass any organic sample that contains or contained microbial organisms serving as possible C. elegans food source, including fruits, plant stems and leaves, compost, animal carcasses, animal feces. Fruits in advanced stages of decomposition on the ground represent ideal target samples due to their high microbial content and likely also because they attract diverse invertebrates that might carry Caenorhabditis nematodes [5]. Direct sampling of such invertebrate carriers (arthropods, including insects, isopods as well as mollusks, such as snails or slugs) has yielded C. elegans and other Caenorbabditis species $[5,6,12]$. Sampling success is highest for rotting fruit/plant material that is not dry and not directly exposed to sun light.

1. Using disposable plastic gloves, collect samples from suitable habitat (see above) and place into container, ideally transparent plastic zip-lock bags for plant substrates (for invertebrates, use hard plastic containers, e.g., Falcon tubes). Leave ample air in the bag and add some paper towel if the sample is very liquid, to avoid fermentation.

2. Note date of collection, locality (e.g., GPS coordinates), habitat, and substrate type (e.g., take photographs). 


\subsection{Nematode Isolation in the Laboratory}

3.4 Morphological and Molecular Identification of C. elegans
3. Store samples in the dark, and keep at temperatures of 15-25 ${ }^{\circ} \mathrm{C}$ (above $25^{\circ} \mathrm{C}$ may lead to sterility in C. elegans). Before processing in the laboratory, substrate samples may be stored for several weeks in plastic bags but samples should be regularly aerated. For high success in nematode recovery, analyze substrates within 1 week after sampling.

1. Place substrate samples on large (e.g., $100 \mathrm{~mm}$ diameter) NGM plates seeded with a spot of E. coli OP50 in the center of the plate. Tear up or cut large samples into smaller pieces and place them around the E. coli spot (sacrifice live invertebrates). Add 1-3 mL of clean water or M9 buffer onto the substrate. Avoid damaging the agar plates as this will facilitate burrowing of nematodes into the culture plates, making subsequent visual observation difficult. Cover the plate with lid. Samples, such as rotting fruit, usually contain diverse invertebrates (e.g., mites, insect larvae, flies): to avoid their spread and cross-contamination among plates, wrap plates with Parafilm. Keep samples at $15-20^{\circ} \mathrm{C}$.

2. Bactivorous nematodes, such as C. elegans, will crawl onto the E. coli lawn and can be easily observed using a standard dissecting stereomicroscope equipped with a transmitted light source. Nematodes may colonize the E. coli lawn within minutes to hours after placing the sample on the culture plate, but for samples with low densities (or individual dauer individuals) it may take several days to detect the nematodes. Keep sampling plates for 5-7 days and, after nematode isolation, autoclave before disposal.

3. Check for the presence of nematodes on the plate using a dissecting scope. Diverse bacteria and fungi stemming from the sample will also grow on the NGM plate, making observation difficult over time ( see Note $\mathbf{l}$ ). If this is the case, cut out a piece of agar containing nematodes and transfer to a new plate to facilitate visual observation.

4. Pick individual nematodes to fresh NGM plates $(55 \mathrm{~mm}$ diameter) using a platinum worm pick and amplify population (see Note 2).

The following protocol for rapid and easy identification of C. elegans uses minimal morphological knowledge of C. elegans allowing an efficient initial elimination of nematodes that do not represent members of the genus Caenorhabditis. In a second step, only nematodes with a hermaphroditic mode of reproduction are selected. After these two initial steps of selection, analysis using speciesspecific DNA sequence-tag is performed to distinguish between different hermaphroditic Caenorhabditis species [8], which are morphologically very similar. Currently, only three androdioecious 
(hermaphrodite-male) Caenorhabditis species have been described: C. elegans, C. briggsae, and C. tropicalis (C. sp. 11); all other species $(>23)$ show a gonochoristic (female-male) mode of reproduction $[8,21]$. For a detailed overview of Caenorbabditisidentification methods, see [6].

1. Diverse nematode taxa may be uncovered in substrate samples, but a given sample often contains only one or two different nematode species. To check whether picked nematodes may represent C. elegans, use the following two criteria:

(a) The pharyngeal head region contains two distinct bulbs: the middle and the basal pharyngeal bulbs, the latter bulb exhibits a grinder (Fig. 2). This morphology is typical for all Caenorbabditis species [6] and can be examined using a dissecting scope at $50 \times$ or higher magnification (or using light microscopy).

(b) Test whether reproduction occurs through self-fertilizing hermaphrodites: isolate juvenile stages onto individual NGM plates and determine whether fertile progeny is produced after a $2-5$ days of growth at $20^{\circ}$. (For isolation of gonochoristic Caenorbabditis species, see Note 3 ).

Note that several additional simple morphological criteria (e.g., long and pointy tail, central vulva, oval embryos) are characteristic for Caenorbabditis and may also be used for identification [6]; for detailed morphological characterization of Caenorbabditis species, see [8, 22, 23].

Caenorhabditis

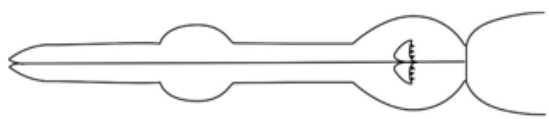

Oscheius

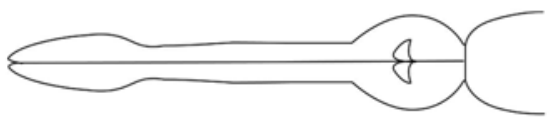

Teratocephalus

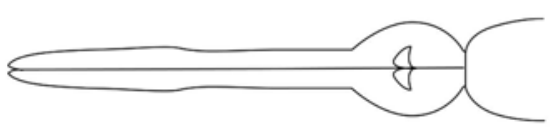

Cephalobidae

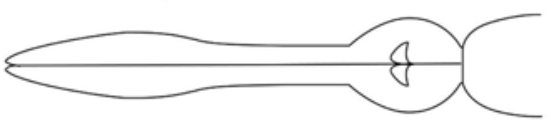

Panagrolaimidae

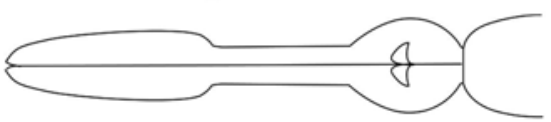

Diplogasteridae

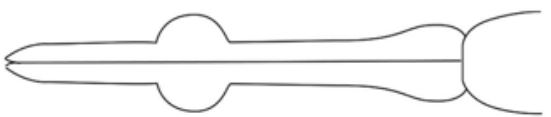

Fig. 2 Morphological characteristics of the $C$. elegans pharynx compared to a selection of other nematode taxa (adapted from [6, 24]). The presence of two circular pharyngeal bulbs is a distinctive feature of Caenorhabditis species and can be observed using a dissecting stereomicroscope at $>50 \times$ magnification and good illumination. Commonly found in the same habitat/substrate are nematodes of the genus Oscheius, which superficially show an overall morphology and size similar to $C$. elegans, yet present a clearly different pharyngeal structure 
2. Molecular identification of C. elegans: Kiontke et al. [8] have established a Caenorhabditis species barcoding method using sequencing of the ITS2 (Internally Transcribed Spacer) region, localized between the $5.8 \mathrm{~S}$ and $28 \mathrm{~S}$ rDNA genes. To amplify the region of approximately $2 \mathrm{~kb}$, use the following primers:

\subsection{S-1: 5' -CTGCGTTACTTACCACGAATTGCARAC. and}

KK28S-4:5'-GCGGTATTTGCTACTACCAYYAMGATCTGC.

Sequence the amplified fragment with the sequencing primer KK-28S-22 (5'-CACTTTCAAGCAACCCGAC) [8].

Use NCBI Blast to check for species identity of sequence. Caenorhabditis ITS2 sequences are highly species-specific and isolates of a given species differ by a maximum of two nucleotide polymorphisms [8].

\subsection{Genetic Identification Through Crosses with} Established C. elegans Strains

\subsection{Establishment and Cryopreservation of C. elegans Wild Isolate Stocks}

In combination with ITS2 sequence analysis (Subheading 3.4), or as an alternative, presumptive C. elegans species identity of a new isolate can be verified through crosses with known C. elegans strains, e.g., the reference strain, N2 (available from the CGC). Place three to four L4 hermaphrodites of the new isolate together with five to ten males of the identified C. elegans strains, and vice versa. The presence of a high proportion of males (>30 \%) in the Fl progeny indicate successful crossing, thus confirming C. elegans species identity.

(Note that C. elegans does not produce any cross progeny with any other known Caenorhabditis species.)

1. Strain establishment: derive any new C. elegans isolate (i.e., strain) from an isolated single L4 stage hermaphrodite and amplify resulting populations over $4-5$ generations, so that isolates can be considered nearly isogenic [6]. Unless individuals are isolated within hours after sampling, it is advisable to derive only a single isolate from a given sampling bag/unit. Given that $C$. elegans proliferates very rapidly, also within the sample after collection, this procedure limits strain establishment of isolates with identical genotypes. Each new C. elegans isolate should have a unique name, ideally following C. elegans strain naming procedures, i.e., Lab name abbreviation followed by number ID [20].

2. Cryopreservation: All Caenorhabditis species can be cryopreserved [6] using standard C. elegans protocols, and stored at $-80{ }^{\circ} \mathrm{C}$ and liquid nitrogen [20]. For a given isolate to be frozen, grow 5-10 NGM plates (55 $\mathrm{mm}$ diameter) until starvation when cultures contain a maximum of freshly starved L1 animals. Collect individuals from plates using M9 buffer and place solution into sterile test tube (e.g., $15 \mathrm{~mL}$ Falcon tube) and place on ice for $15 \mathrm{~min}$. Centrifuge tube and keep $3 \mathrm{~mL}$ of solution containing worms, then add an equal volume 
of Freezing Solution to tube and mix well. Aliquot mixture to three cryovials, labeled with strain name. Place cryovials in a small Styrofoam box with slots for holding microtubes (to ensure slow freezing of the worms) and place box in a $-80^{\circ} \mathrm{C}$ freezer overnight. Transfer tubes to stock collections at $-80^{\circ} \mathrm{C}$ or liquid nitrogen.

3. Database entry: Add strain information of newly discovered C. elegans wild isolates to Wormbase using the following form: http://tazendra.caltech.edu/ azurebrd/cgi-bin/forms / wild_isolate.cgi.

\section{Notes}

1. To limit fungal contaminations on NGM plates, add $0.01 \%$ thimerosal to water or M9 solution used to moisten the substrate samples.

2. Substrates may harbor diverse microbes that are pathogenic to C. elegans [5]. C. elegans and other nematode species therefore may show pathologies preventing development or growth, and may also complicate morphological analysis. Moreover, many bacterial contaminants generate thick films on NGM plates rendering observations difficult. To generate clean plates and C. elegans cultures, use $\mathrm{NaOH}$-sodium hypochlorite mixture to decontaminate [20].

3. To isolate gonochoristic Caenorhabditis species, place either a single mated female (often visible by the presence of a mating plug) or a female plus male to a fresh plate. For detailed isolation methods of gonochoristic Caenorbabditis species, see [6].

\section{Acknowledgments}

This protocol makes use of diverse contributions from the worm community and is primarily based on Caenorhabditis isolation methods established by Antoine Barrière and Marie-Anne Félix. Our research is financed by the Centre National de la Recherche Scientifique, France.

\section{References}

1. Gaertner BE, Phillips PC (2010) as a platform for molecular quantitative genetics and the systems biology of natural variation. Genet Res (Camb) 92:331-348
2. Andersen EC, Bloom JS, Gerke JP et al (2014) A variant in the neuropeptide receptor npr-l is a major determinant of Caenorbabditis elegans growth and physiology. PLoS Genet 10, e1004156 
3. McGrath PT, Xu Y, Ailion M et al (2011) Parallel evolution of domesticated Caenorhabditis species targets pheromone receptor genes. Nature 477:321-325

4. Andersen EC, Gerke JP, Shapiro JA et al (2012) Chromosome-scale selective sweeps shape Caenorhabditis elegans genomic diversity. Nat Genet 44:285-290

5. Félix M-A, Braendle C (2010) The natural history of Caenorhabditis elegans. Curr Biol 20:R965-R969

6. Barrière A, Félix M-A (2014) Isolation of C. elegans and related nematodes. In: The C. elegans Research Community (ed) Wormbook. http://dx.doi.org/10.1895/wormbook. 1.115 .2

7. Gimond C, Jovelin R, Han S et al (2013) Outbreeding depression with low genetic variation in selfing Caenorhabditis nematodes. Evolution 67:3087-3101

8. Kiontke K, Félix M-A, Ailion M et al (2011) A phylogeny and molecular barcodes for Caenorbabditis, with numerous new species from rotting fruits. BMC Evol Biol 11:339

9. Dolgin ES, Felix MA, Cutter AD (2008) Hakuna Nematoda: genetic and phenotypic diversity in African isolates of Caenorhabditis elegans and C. briggsae. Heredity 100: 304-315

10. Anderson JL, Albergotti L, Ellebracht B et al (2011) Does thermoregulatory behavior maximize reproductive fitness of natural isolates of Caenorbabditis elegans? BMC Evol Biol $11: 157$

11. Barrière A, Félix M-A (2005) High local genetic diversity and low outcrossing rate in Caenorbabditis elegans natural populations. Curr Biol 15:1176-1184

12. Barrière A, Félix M-A (2007) Temporal dynamics and linkage disequilibrium in natural C. elegans populations. Genetics 176: 999-1011

13. Felix MA, Duveau F (2012) Population dynamics and habitat sharing of natural populations of Caenorhabditis elegans and $\mathrm{C}$. briggsae. BMC Biol 10:59

14. Haber M, Schüngel M, Putz A et al (2005) Evolutionary history of Caenorbabditis elegans inferred from microsatellites: evidence for spa- tial and temporal genetic differentiation and the occurrence of outbreeding. Mol Biol Evol 22:160-173

15. Petersen C, Dirksen P, Prahl S et al (2014) The prevalence of Caenorhabditis elegans across 1.5 years in selected North German locations: the importance of substrate type, abiotic parameters, and Caenorbabditis competitors. BMC Ecol 14:4

16. Sivasundar A, Hey J (2005) Sampling from natural populations with RNAI reveals high outcrossing and population structure in Caenorhabditis elegans. Curr Biol 15: 1598-1602

17. Caswell-Chen EP, Chen J, Lewis EE et al (2005) Revising the standard wisdom of $C$. elegans natural history: ecology of longevity. Sci Aging Knowl Environ 40:pe30

18. Felix MA, Jovelin R, Ferrari C et al (2013) Species richness, distribution and genetic diversity of Caenorhabditis nematodes in a remote tropical rainforest. BMC Evol Biol $13: 10$

19. Kiontke K, Sudhaus W (2006) Ecology of Caenorhabditis species. The C. elegans Research Community (ed) Wormbook. http://dx.doi.org/10.1895/wormbook. 1.37 .1

20. Stiernagle T (2006) Maintenance of C. elegans. The C. elegans Research Community (ed) Wormbook. http://dx.doi.org/10.1895/ wormbook.1.101.1

21. Felix MA, Braendle C, Cutter AD (2014) A streamlined system for species diagnosis in Caenorhabditis (Nematoda: Rhabditidae) with name designations for 15 distinct biological species. PLoS One 9, e94723

22. Sudhaus W, Fitch D (2001) Comparative studies on the phylogeny and systematics of the Rhabditidae (Nematoda). J Nematol 33:1-69

23. Sudhaus W, Kiontke K (1996) Phylogeny of Rhabditis subgenus Caenorhabditis (Rhabditidae Nematoda). J Zoo Syst Evol Res 34:217-233

24. Chiang JT, Steciuk M, Shtonda B et al (2006) Evolution of pharyngeal behaviors and neuronal functions in free-living soil nematodes. J Exp Biol 209:1859-1873 